\title{
Digital Transformation Of Financial Sector And Challengies For Competencies Development
}

\author{
Inese Mavlutova* \\ Economics and Finance department \\ BA School of Business and Finance \\ Riga, Latvia \\ 0000-0002-3245-9540
}

\author{
Tatjana Volkova \\ Management department \\ BA School of Business and Finance, \\ Riga, Latvia \\ 0000-0002-7599-8720
}

\begin{abstract}
The development of Information and communication technologies (ICT), AI and robotics has a significant impact on the competencies of companies operating in financial sector. Digital transformation leads to changing existing competencies rapidly, as well as necessity of developing new competencies specifically related to the use of ICT, Artificial intelligence and robotics in business processes, development of new products and updating existing ones.

The purpose of research is to investigate the challenges for development of competencies in the financial sector impacted by the development of ICT, AI, Robotics and other knowledgeintensive technological solutions.

The application of new technologies is topical for companies, especially those the financial sector. New technologies related to the digitalization of business processes, automatization and the use of Artificial intelligence require different competencies from managers and specialists, such as computer science, big data analysis, predictive analytics, cybersecurity, co-creation, working with virtual assistants among others.
\end{abstract}

Keywords-competencies, financial sector, information and communication technologies, robotics, artificial intelligence, digitalization.

\section{INTRODUCTION}

The development of specific competencies ensuring digital transformation of financial sector has become one of the most pressing challenges for ensuring competitiveness and sustainable business. Today, changes in the demand for ICT, AI and robotics related competencies in financial sector are observed both through the development of different technologies and their application in the enterprise core or ancillary processes (e.g. customer service and other processes automation, more refined marketing offerings, product positioning for segmented customer groups) and improvement of existing products and development of new products. Based on the opportunities empowered by ICT, AI and robotics the development of new competencies is needed to transform these opportunities into new products and services meeting changing demand of customers in the financial sector.

The purpose of research is to investigate the challenges for development of competencies in the financial sector impacted by the development of ICT, AI, robotics and other knowledge-intensive technological solutions.
The objectives of the research are to study the nature of managerial and specialists' competencies in the financial sector and to identify key aspects of the impact of ICT, AI and robotics on the required financial sector competencies, develop guidelines for further research on competence management.

Research methodology: systematic review of scientific literature, statistical data analysis, survey's analysis and structured interviews.

\section{THE ESSENCE OF COMPETENCIES AND ITS MANAGEMENT}

Today, the professional leadership and sustainability of organizations require managers and professionals to possess varying degrees of competencies, which are changing rapidly due to the new technologies available requiring different kind of business solutions.

Competence is a rather complex concept. The term "competence" first appeared in an article authored by R.W. White [1] in 1959 as a concept for performance motivation. In the scientific literature competencies are considered both as a set of capabilities and as a qualification for fulfilling certain tasks. According to A. Wieczorek-Szymańska [2] the employee's competencies are defined as employees' disposal that refer to the knowledge, skills and attitudes that enable employee to fulfill professional duties on required level. The usage and the development of competencies in the work process led to accomplishment of the organizational goals that are formulated in the strategy.

The authors agree with M. Mulder's [3] definition that competence is the set of integrated capabilities which consist of content-related clusters of knowledge, skills and attitudes and are conditional for sustainable effective performance (including problem solving, realizing innovation, and creating transformation) in a certain context, profession, organization, job, role and situation.

Competencies lies within the individual, the group, and the organization levels. A. Wieczorek-Szymańska [2] believes that competence profiles include three categories of competencies: organizational, professional and social competencies. Organizational competencies that are common for all employees in the organization no matter the job position, for example: self-identification with organization, the knowledge of vision and mission of the organization, results orientation etc. Professional competencies that refer to particular knowledge, experience, skills that are important 
for the job position, for example: the ability to speak foreign languages. Social competencies that are so called soft competencies, for example: the ability to work in group.

According to E. Lamarque [4], in general, there are two main subgroups of competences in the scientific literature:

- competencies that the consumer faces directly with the products offered: the security of the transactions, the effectiveness of the distribution network and public relations features, as well as personal knowledge and others;

- internal competencies that are difficult to comprehend, such as information systems concept, rationalization of cost structure and the ability to assess and control risk.

From the authors point of view, both approaches to group competencies are relevant as A. Wieczorek-Szymańska is grouping competencies around individual, group and organizational levels and competence profiles, but $\mathrm{E}$. Lamarque is looking to competencies from external and internal organizational perspective. As there are different levels of competencies: a higher level of competencies is required for a company to improve its performance.

There is no common understanding of what competencebased management is currently. M. Harzallah [5] et al. consider competence management as a way for the organization to manage the competencies at the organizational, group and individual levels. They developed a three-step competence management model that consists of competence identification, competence assessment and competence usage.

R. Medina and A. Medina [6] continued to develop M. Harzallah et.al. and defined the stages of competence management such as 'selection', 'training and development', 'performance appraisal' and 'internal promotion' of staff, thus considering a competence management as a sub-function of human resource management, [7].

The authors support M. Harzallah et al. idea to develop the competence management model and to adapt it to financial sector. It is already clear that, in addition to the 3 competencies management processes (competence identification, assessment and usage) mentioned above, it needs to be complemented by performance evaluation and feedback in the light of new circumstances to ensure competencies transformations.

\section{COMPETENCIES IN FINANCIAL INSTITUTIONS}

P. Drucker [8] defined the banking business as the point at which supply and demand meet the intention to integrate internal and external analysis of the enterprise. The supply system is needed to support market conditions and the competencies of the company management, it must be able to meet the needs of the companies.

The authors also examined the classical types of competencies by studying the competencies profile for retail banking. As it can be seen form Table 1, the competencies of commercial bank managers and specialists are divided into five main subgroups related to the market in general and customer research, legal knowledge (contracts), specific competencies in financial situation regarding research and ability to advise clients also the bank's internal procedures risk control, use of technology, etc.

All these subgroups of competencies are impacted by new technologies thus requiring different kind of competencies on individual, group and organizational levels in the context of digital transformation.

Financial institutions operate in a knowledge and technology intensive sector that is changing rapidly due to new technologies, customer needs, regulatory requirements, etc. Requirements for the specific competencies for both commercial bank employees and their managers are also changing rapidly.

R. Gregory [9] et al. believe that banks face increasingly stringent regulatory and complex requirements in order to limit business risks. To comply with this requirement, robust governance and complex IT infrastructures must be ensured.

According to the Digital Banking report 2019 Retail banking trends and predictions based on the survey for the first time ever among strategic priorities for 2019, the use of big data, AI and advanced analytics was ranked first, replacing improving the customer experience as the number one trend for the previous year.

TABLE I. THE COMPETENCIES PROFILE IN THE COMMERCIAL BANKS

\begin{tabular}{|c|c|}
\hline Subgroups & Competencies \\
\hline $\begin{array}{l}\text { Basic } \\
\text { competencies }\end{array}$ & $\begin{array}{l}\text { Physical or electronic networking } \\
\text { Knowledge about consumer background } \\
\text { Segmentation of market according to risk control, } \\
\text { expectations, profitability } \\
\text { Automation of operations } \\
\text { Technological control in products and services }\end{array}$ \\
\hline $\begin{array}{l}\text { Distinctive } \\
\text { competencies }\end{array}$ & $\begin{array}{l}\text { Sufficiently decentralised networking and specialised } \\
\text { distribution channels } \\
\text { Optimal inter-knitting of the network: } \\
\text { offer/client/channel } \\
\text { Forecasting } \\
\text { Analysis of consumer database (Information system) } \\
\text { Identification of profit-making sectors } \\
\text { Product and process innovation } \\
\text { Combining services and products in a package } \\
\text { Structure of branches } \\
\text { Public image } \\
\text { Capacity to guarantee consumer commitments } \\
\text { Cost structure of institution } \\
\text { Knowledge of cost price }\end{array}$ \\
\hline $\begin{array}{l}\text { Specific } \\
\text { competencies: } \\
\text { fund raising }\end{array}$ & $\begin{array}{l}\text { Capability of staff to advise consumers } \\
\text { Capacity to make the consumers feel secure } \\
\text { Structuring product range } \\
\text { Placing and managing funds raised }\end{array}$ \\
\hline $\begin{array}{l}\text { Specific } \\
\text { competencies: } \\
\text { credit }\end{array}$ & $\begin{array}{l}\text { Understanding of scores and quotation procedures } \\
\text { Correct invoicing of risk } \\
\text { Finding resources at best cost } \\
\text { Differentiated offer: flexible products, possibility to } \\
\text { renegotiate }\end{array}$ \\
\hline $\begin{array}{l}\text { Specific } \\
\text { competencies: } \\
\text { private } \\
\text { investor } \\
\text { banking }\end{array}$ & $\begin{array}{l}\text { Control of invoicing: cost knowledge } \\
\text { Automation of operations } \\
\text { Insurance and consumer help systems } \\
\text { Direct banking, Internet, telephone }\end{array}$ \\
\hline $\begin{array}{l}\text { Specific } \\
\text { competencies: } \\
\text { private } \\
\text { investor } \\
\text { banking }\end{array}$ & $\begin{array}{l}\text { Control of invoicing: cost knowledge } \\
\text { Automation of operations } \\
\text { Insurance and consumer help systems } \\
\text { Direct banking, Internet, telephone }\end{array}$ \\
\hline
\end{tabular}


In addition, there was a realization of the importance of open banking and APIs by organizations globally. Finally, the importance of innovation was also a trend that increased in importance [10].

Consequently, financial sector managers need to provide pro-active and effective competence-based management to ensure that the proper competencies are in place for achieving the business development goals and demonstrate high business performance in both the short and long term.

\section{THE IMPACT OF DIGITAL TRANSFORMATION ON FINANCIAL SECTOR AND REQUIRED COMPETENCIES}

Currently, commercial banks are competing with technology start-ups (FINTECHs), whose products overlap with those offered by banks. With the rapid development of technology, they have also entered the financial services sector, thus making customers lives more comfortably. Although technology start-ups may not be able to fully utilize banking services in their technology solutions, they still create products where the user is not tied to a particular bank as a customer.

The position of financial technology companies in the financial services sector and their relationships with traditional financial services providers (banks) in the context of a global, diverse and rapidly growing supply of digital innovations is now described not only as competitive relationships but also as a collaborative or partnership relationships. From the perspective of the development of traditional financial service providers, the current situation is increasingly dominated by the trend not to question about the need for digital transformation, as well recognition about the significantly greater flexibility and innovation potential of financial technology start-ups.

I. Anagnostopoulos believes that FINTECHs have reached the main channels of commercial banks through technology and innovation in the financial sector. B. Drasch [12] et al. agree with I. Anagnostopoulos [11] that banks are struggling with innovation opportunities, while FINTECHs offer technology-enabled capabilities, thus disrupting the value propositions of classical banks.

It should be noted that some of the financial technology start-up solutions are designed to be integrated into banking processes or services (technological solutions for AML risk analysis, customer remote identification tools, etc.). Some of the innovations extend the ability for customers to combine traditional banking with functionality that comes from their business operations (such as shopping or selling). Of course, there are also duplicated services that FINTECH companies can offer in a much more efficient way, e.g. more convenient and faster. However, the situation in recent years is characterized by the trends and opportunity for each of the national "camps" in the financial services sector to deliver services in their niches and to cooperate more, complement each other rather than compete.

In the light of the above trends, the authors note that both traditional banks adopting a digital transformation dictation and FINTECH companies have their own specifics in absorbing or creating new technologies that provide opportunities to develop or integrate more or less explicit knowledge-intensive technologies on a narrower spectrum, building on this basis its competitive advantage [13]. Such specificities imply specific and divergent competence needs as well as an appropriate organizational structure.

It plays an important role today in robotic process automation, the use of specialized computer programs known as software robots to robotize standardized, iterative processes. It is one of the most up-to-date and promising technologies that can change the mindset of professionals when it comes to manual work. This technology is based on three components: robot, process and automation. A robot in this context is software that is capable of performing programmed operations (processes) on it that are performed by an employee. Except for software development, the process is fully automated, without employee involvement [14].

The introduction of robotic process automation allows to increase the efficiency of business operations and thus decreasing costs. Robotic process automation can be an important factor in solving automation problems, while promoting enterprise digitalization. However, it is only one of the mechanisms of digital transformation of enterprises. Robotics not only automates day-to-day monotonous tasks, but in combination with business process management technologies, enables businesses to reach ever greater potential. Robotization must be distinguished from AI, which can be defined as a program capable of automating an employee's field of activity in which the robot is able to keep up with humans [15].

Researching the scientific and industry literature, the authors came to the conclusion that the concepts of business process automation, robotics and $\mathrm{AI}$ are often confused.

The financial sector was one of the first to stimulate interest in the use of AI. 20th century in the 1950s, interest in the potential of automation emerged as it could help accountants and bankers speed up their work by helping them analyze, calculate, and process data. In the $60 \mathrm{~s}$ of the 20th century, many studies focused on Bayesian statistics, a method used mainly in machine learning. Some of its applications involved stock market forecasting. Already in the $80 \mathrm{~s}$ of the 20th century, at least one third of Fortune companies had one AI project.

The main features of AI can be highlighted in the following definitions:

- $\mathrm{AI}$ is a computerized system that demonstrates behaviors typically associated with intelligence, such as visual perception, speech recognition, decision making, and translation between different languages;

- $\mathrm{AI}$ is the science of how machines perform tasks that require the presence of intelligence;

- AI is the science of creating intelligent machines (computers) to create computer programs [16].

The AI System combines and utilizes mainly machine learning (the usage of computer systems to perform specific tasks efficiently without relying on clearly programmed instructions), smart machines (devices that are embedded with machine networking and / or cognitive computing technologies and able to make their own decisions without requiring human contribution) and other data analysis 
techniques to achieve AI capabilities such as big data analysis, is able to justify the situation (deductively and inductively) and draw conclusions based on the situation; able to communicate in different languages; able to analyse and solve complex problems.

It follows from the definitions considered that $\mathrm{AI}$ is the most important factor in the development and operation of the above listed processes and technologies (see Fig. 1) and cannot exist without robotics and vice versa. The authors emphasize that robotization is, after all, a technology based on predecessor technologies such as AI, screen scraping and workflow automation, in which these technologies combine and bring new quality, significantly improving their capabilities.

Despite the fact that AI solutions are currently in their infancy, most financial institutions already use AI solutions in data processing, credit risk rating, opening accounts, communication with clients and payment processing, currencies control, blockchains, handling requests from the executive institutions, etc.

Thus, the British HSBC Bank introduced robots that detect money laundering, fraud and terrorist financing. The Bank plans to integrate artificial intelligence software to detect suspicious activity using big data. HSBC Bank uses AI to predict how customers will redeem their credit card points so they can more actively and efficiently market their offers. Categories such as travel, merchandise, gift cards or money are usually offered.

One of Europe's largest banks introduced AI as a bond trading tool that helps them get bond prices quickly. Within six months, the AI tool helped people make faster decisions while reducing their marketing costs by $25 \%$. Deutsche Bank has developed a new AI-based stock algorithm platform, $A P A C$, which was developed with a self-learning mechanism that enables systems to predict stock price with greater precision, thereby improving execution quality [18].

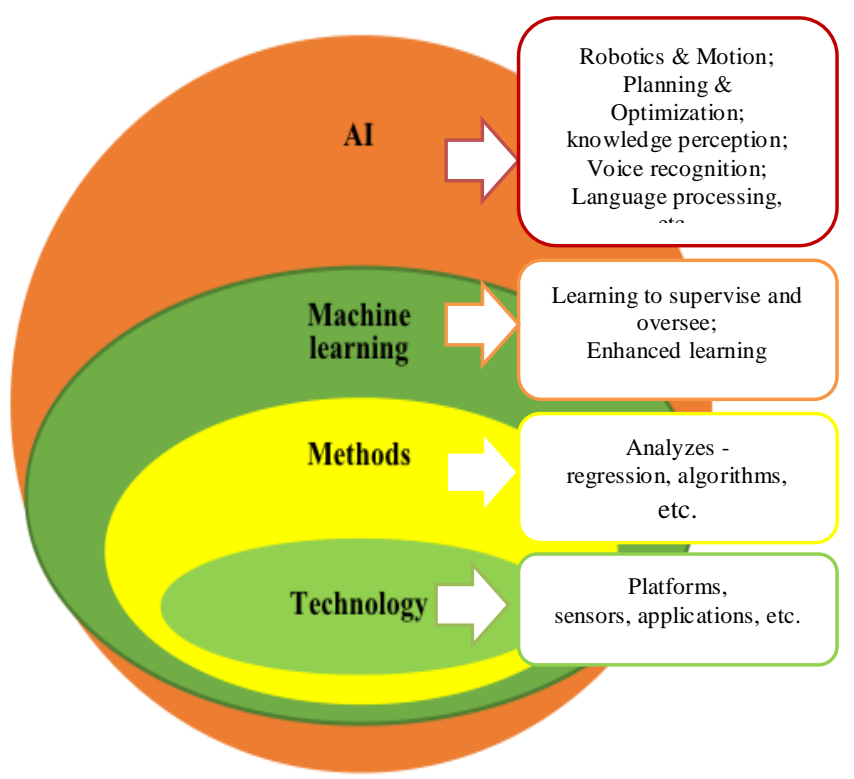

Fig.1. Components of Artificial Intelligence [17]
Currently, the banking industry is investing heavily in AI product acquisition and development. For example, in 2015, bank spending on AI products already exceeded all other industries (see Fig. 2). Experts at Bloomberg Intelligence predict banks 'costs will outweigh other industries' costs for AI products up to 2020.

Nowadays, there is a global assumption that FINTECHs are not yet in a position to bring serious competition to banks, and that these are stand-alone products that have been made more convenient. FINTECHs are not engaged in the basic business of banks - attracting deposits and lending loans. However, in the future, banks will have to look at products offered by FINTECHs, as some users will find them more convenient. True, today banks are still with much greater market share and responsibility for economic events. Nevertheless, this situation could be challenged too by fast development of FINTECHs.

At the same time, it must be acknowledged that FINTECHs would not bear any responsibility for economic processes that would, for example, worsen a country's economy or have some other wider effect. In other words, FINTECHs are now more focused on improving certain services and making them more convenient or cheaper for customers rather than directly competing with banks [19].

In the meantime, there are also start-ups that are not going to stop at one product offering. For example, in the Baltics Revolut has entered the market, applying for and obtaining a banking license in Lithuania as an alternative to payment cards issued by banks [20]. This shows that this company has a vision to make banking services better, more accessible or cheaper for its customers.

The way banks learn to use their intangible and tangible assets, including the competencies of managers and professionals, to create an attractive, customer-oriented service will play an important role in this competition [22].

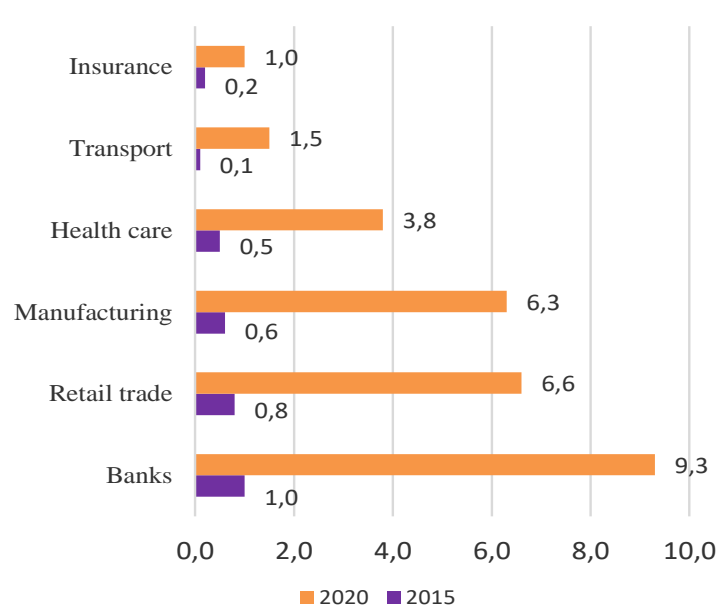

Fig. 2. Sector spending on artificial intelligence products, billions of dollars [21] 
When implementing robotics, it is important for the team to be knowledgeable about this technology, to be able to supplement it with their knowledge of an existing, manual process that would allow them to develop a high-quality algorithm, which in turn could be used for robot programming. Cloud technology, process automation and robotics are expected to have the greatest economic impact in the future.

Deloitte's 2017 report, based on a survey of more than 400 companies from a variety of industries across the Internet, has been used as a key strategic priority for companies in 2017 in their exploration of new innovative technologies for business process digitalization, automation, and AI worldwide and process automation and robotization compared to 2016 [17].

As Fig. 3. shows, management's emphasis on developing data analytics, as reported by $17 \%$ of respondents, as well as desire for automation, has increased.

For getting practical insights into automation, robotics, and AI, researchers of BA School of Business and Finance conducted interviews with financial sector experts, asking a total of 6 questions to clarify views on various aspects of digitalization, automation, robotics and AI related issues at the end of 2018 .

With regard to the challenges that companies need to be prepared to embark on in the implementation of robotics and AI, all experts believe that it is important to have a team with the appropriate competencies that can provide both process development and maintenance by structuring and providing control over change management.

It is important to note that even before the introduction of new technologies there is a need to develop necessary competencies and to assign responsible person or structure for the implementation of new processes. In case of implementation of robotics, for example, is rather easy to introduce because it requires no programming knowledge from staff and can use already existing enterprise applications. Although the new competencies are required to work alongside with robotics, e.g. in case with virtual assistants demonstrating the new roles of employees.

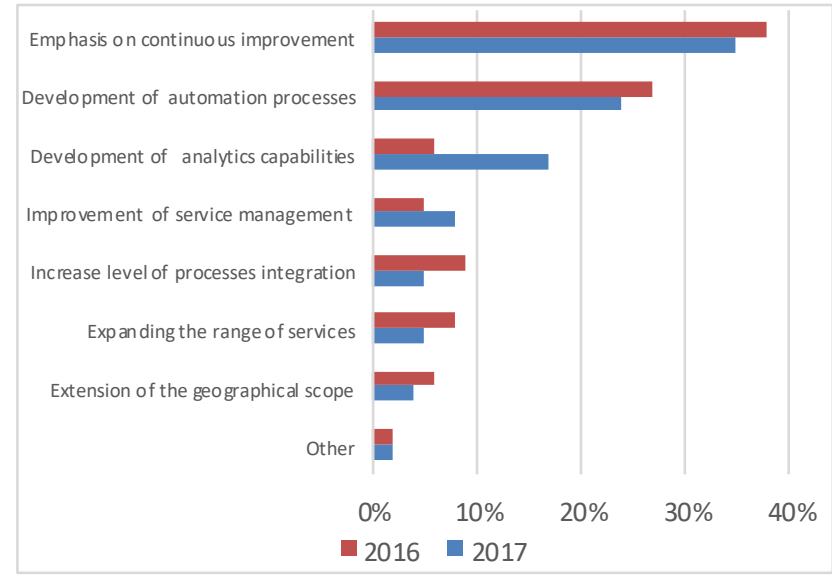

Fig. 3. Main strategic priorities for the large and medium-sized enterprises in the world for 2016-2017yy

Source: compiled by the autors using [17]
Experts argue that it is more beneficial to use existing professionals in process of robotics, to train them as they already have process knowledge, and that employees will be more interested in developing their competencies and career in the robotics environment.

Due to the impact of technologies mentioned in the article many new professions are occurring like digital process designer, digital products managers, digital solutions architects, customer digital experience manager, etc. requiring obtaining new competencies for fulfilling their roles and responsibilities. It is necessary to add that the necessary set of competencies and competence level required are closely related to the particular job functions.

From the authors point of view, the banking sector would benefit from development of following competencies like big data analysis thus allowing to explain complex data, present solutions based on advanced analysis to enable better decisions for increasing business performance; predictive analytics for empowering insight into customer behaviour, improving supply chain, fraud detection; cybersecurity competencies; competencies for working with virtual assistants; competencies for usage co-creation as a tool to deliver innovative solutions across the whole value chain, etc. In order to differentiate the services offered the distinctive competencies have to be developed by commercial banks. Distinctive competencies could be created around any value chain activity, e.g. customer experience design, value delivery channels among others.

According to C. Giebe [23], businesses in the banking market need to think about how to effectively manage financial sector digital transformation. One way to do so, is the implementation of the role of a Chief Digital Officer (CDO) within the managerial board. From the authors point of view, introduction of Innovation Centers or Chief Innovation Officers (CIO) would be more beneficial in case of commercial banks digital transformation.

\section{CONCLUSIONS}

During the study, the authors came to the conclusion, that competence is a rather complex concept. Competence is the set of integrated capabilities which consist of content-related clusters of knowledge, skills and attitudes and are conditional for sustainable effective performance.

The application of new technologies is topical for companies, especially those working in the financial sector. However, the scientific and professional literature lacks a common understanding of the differences between process technologies and their applications, and its robotization which is mixed with similar but unequal technologies such as AI, robotics, process automation, etc.

Given the size of organizations, the financial sector, especially FINTECH's in today's world, is the main user of new innovative technologies related to business process digitalization, automatization and the use of AI.

Financial sector managers need to provide pro-active and effective competency- based management to ensure that the proper competencies are in place for achieving the business development goals. 
New technologies related to the digitization of business processes, automation and the use of AI require different competencies from managers and specialists of financial institutions, such as computer science, big data analysis, predictive analytics, cybersecurity, co-creation, working with virtual assistants among others.

\section{ACKNOWLEDGMENT}

This paper was supported by the BA School of Business and Finance Internal Research Project" The Assessment of Competence Management in the Latvian Financial Sector".

\section{REFERENCES}

[1] R. W. White, "Motivation Reconsidered The Concept of Competence ”б Psychological Review, 66, 1959, pp. 297-333.

[2] A. Wieczorek-Szymańska, "Reports on Economics and Finance," Vol. 1, no. 1, HIKARI Ltd , 2015, pp. 105 - 113www.m-hikari.com,. [Online] Available: http://dx.doi.org/ 10.12988/ ref .2015.51111. Accessed on: August 12, 2019.

[3] M. Mulder, "The concept of competence: blessing or curse?" in Innovations for competence management, Conference Proceedings. I. Torniainen, S. Mahlamäku-Kultanen, P. Nokelainen and P. Ilsley Eds. Lahti: Lahti University of Applied Sciences, 2011, pp. 11-24.

[4] E. Lamarque, “ Key Activities in the Banking Industry: Analysis by the Value Chain," in Revue Finance Contrôle Stratégie, 1999, vol. 2, issue 2, 1999, pages 135-158.

[5] M. Harzallah, G. Berio, and F. Vernadat, "Analysis and modeling of individual competencies: toward better management of human resources," in Systems, Man and Cybernetics, Part A: Systems and Humans, IEEE Transactions on, Vol. 36 No. 1, 2006, pp. 187-207.

[6] R. Medina, A. Medina, "Thecompetenceloop: Competence management in knowledge-intensive, project-intensive organizations", International Journal of Managing Projects in Business, Vol. 8 Issue: 2,2015, pp. 279-299, [Online] Available: https://doi.org/10.1108/IJMPB-09-2014-0061. Accessed on: August 12,2019

[7] H.-A. Shih, and Y.-H. Chiang, "Exploring relation ships between corporatecore competence, corporate strategy, and HRM practices in training institutions", in Asia Pacific Management Review, Vol. 8 No. 3, 2003, pp. 281-310.

[8] P. Drucker, "The age of social transformation," in Atlantic Monthly, 1994, pp. 53-80.

[9] R. W., Gregory, E. Kaganer, O. Henfridsson, and T. J. Ruch, "IT Consumerization and the Transformation of IT Governance," MIS Quarterly, 42(4), 2018, pp.1225-1253.

[10] J. Marous, "Retail Banking Trends and Predictions 2019," LLC Issue Number 260, DBR Media, December 2018, [Online] Available: https://www.digitalbankingreport.com/wp-content/uploads/ 2019/01/DBR_260_Abstract.pdf. Accessed on: August 14, 2019
[11] I. Anagnostopoulos, "Fintech and regtech: Impact on regulators and banks," Journal of Economics and Business, Elsvier, vol.100(C), pp. 7-25, November-December 2018, [Online] Available: https://ideas.repec.org/a/eee/jebusi/v100y2018icp7-25.html. Accessed on: August 13, 2019.

[12] B. J. Drasch, A. Schweizer, and N. Urbach, "Integratingthe 'Troublemakers': A taxonomy for cooperation between bank sandfintechs," Journal of Economics and Business, Elsvier, vol.100(C), pp. 26-42, November-December 2018.

[13] I. Lee, and Y. J. Shin, "Fintech: Ecosystem, business models, investment decisions, and challenges", Business Horizons, 61(1), 2018, pp. 35-46.

[14] V. Yedavalli, "Are Robots Helping or Hurting the Future Workforce?", The CPA Journal, 2018. [Online] Available: https://www.cpajournal.com > CPA Journal Content. Accessed on: August 13, 2019.

[15] A. Gupta, "The History of AI in Finance," 2018, [Online] Available: https://medium.com/district3/the-history-of-ai-in-finance7a03fcb4a498. Accessed on: August 12, 2019.

[16] S. van Duin and N. Bakhshi, "Artificial Intelligence Defined. The most used terminology around it," March 2017, [Online] Available: https://www2.deloitte.com/se/sv/pages/technology/articles/part1 artificial-intelligence-defined.html. Accessed on: August 13, 2019.

[17] Deloitte, "Robots are ready, Are you?" 2017, [Online] Available: https://www2.deloitte.com/content/dam/Deloitte/tr/Documents/techno logy/deloitte-robots-are-ready.pdf. Accessed on: August 16, 2019.

[18] E. Mesropyan, "How European Banks Are Using AI", 2018, [Online] Available: https://gomedici.com/how-european-banks-areusing-ai/. Accessed on: August 12, 2019.

[19] Craft driven market research, "Banks And Fintech Startups Collaboration Or Competition?", [Online] Available: http://www.craftdrivenresearch.com/banks-fintech-startups/. Accessed on: August 12, 2019.

[20] Revolut, "We got a banking licence," 2018, [Online] Available: https://blog.revolut.com/we-got-a-banking-licence/. Accessed on: August 13, 2019.

[21] L.Chen, J. Danbolt, and J. Holland, "Rethinking bank business models: the role of intangibles", Accounting, Auditing \& Accountability Journal, Vol. 27 Issue: 3 ,2014, pp.563-589, [Online] Available: https://doi.org/10.1108/AAAJ-11-2012-1153. Accessed on: August 2, 2019.

[22] KPMG, "Bank customer service as a competitive advantage",2018, [Online] Available: https://assets.kpmg/content/dam/kpmg/ kz/pdf/kzbank-customer-service-as-competitive-advantage.pdf. Accessed on: August 14, 2019.

[23] C. Giebe, "The Chief Digital Officer -Savior for the Digitalization in German Banks?" Journal of Economic Development, Environment and People Volume 8, Issue 3, 2019, pp. 6-15. 